\title{
Diosgenin induces G2/M cell cycle arrest and apoptosis in human hepatocellular carcinoma cells
}

\author{
YONGJIAN LI ${ }^{1 *}$, XIAORONG WANG ${ }^{1,2,3^{*}}$, SILU CHENG $^{2 *}$, JUAN DU $^{2}$, ZHENGTING DENG $^{1,2}$, \\ YANI ZHANG ${ }^{2}$, QUN LIU $^{2}$, JINGDONG GAO ${ }^{1}$, BINBIN CHENG $^{2}$ and CHANGQUAN LING ${ }^{2,4}$ \\ ${ }^{1}$ Department of Oncology, Suzhou Hospital of Traditional Chinese Medicine, Suzhou, Jiangsu 215009; \\ ${ }^{2}$ Department of Traditional Chinese Medicine, Changhai Hospital, Second Military Medical University, Shanghai 200433; \\ ${ }^{3}$ The First Clinical Medical College, Nanjing University of Chinese Medicine, Nanjing, Jiangsu 210046; \\ ${ }^{4}$ E-Institute of TCM Internal Medicine, Shanghai Municipal Education Commission, Shanghai 201203, P.R. China
}

Received September 24, 2014; Accepted November 12, 2014

DOI: $10.3892 /$ or.2014.3629

\begin{abstract}
Diosgenin is a major compound of Dioscoreaceae plants such as yam, which is used as a drug in Traditional Chinese Medicine, and a common vegetable worldwide. The anticancer effect of diosgenin has been reported in various tumor cells, including leukemia, gastric, colorectal, and breast cancer. However, the activity of diosgenin on hepatocellular carcinoma (HCC) and the underlying mechanism have not been completely investigated. Therefore, we investigated the efficacy and associated mechanisms of diosgenin in HCC cells. Flow cytometric analysis was performed to determine the presence of cell cycle arrest and apopotic cells. Diosgenin significantly inhibited the growth of Bel-7402, SMMC-7721 and HepG2 HCC cells in a concentration-dependent manner. Diosgenin treatment for $24 \mathrm{~h}$ induced G2/M cell cycle arrest and apoptosis of hepatoma cells. Diosgenin inhibited Akt phosphorylation and upregulated p21 and p27 expression, but did not alter the expression of p53, suggesting diosgenininduced upregulation of p21 and p57 is p53-independent in HCC cells. Diosgenin induced HCC cell apoptosis by activating caspase cascades $-3,-8$ and -9 . However, diosgenin did not affect Bcl-2 and Bax levels. In conclusion, results of the present study suggest that diosgenin may be an active anti-HCC agent obtained from natural plants and provide new insights in understanding the mechanisms of diosgenin.
\end{abstract}

Correspondence to: Dr Binbin Cheng or Professor Changquan Ling, Department of Traditional Chinese Medicine, Changhai Hospital, Second Military Medical University, 168 Changhai Road, Shanghai 200433, P.R. China

E-mail: cbb8202@126.com

E-mail: lingchangquan@hotmail.com

*Contributed equally

Key words: diosgenin, hepatocellular carcinoma, apoptosis, cell cycle arrest

\section{Introduction}

Hepatocellular carcinoma (HCC) is one of the most common malignant tumors in China (1). Although surgical resection remains the optimum option for HCC, many patients are unresectable due to the tumor size, metastasis, hepatic functional reserve and/or portal hypertension. Trans-arterial embolization (TAE), percutaneous injection of ethanol and radiofrequency ablation have also been used in the treatment of unresectable patients. However, these methods only target the local tumors and the high recurrence and metastatic rate limit the outcome. In addition, HCC is not sensitive to most chemotherapeutic drugs, such as paclitaxel, doxorubicin, fuorouracil, cisplatin and mitomycin. Thus, new agents that are safe and effective are to be identified for the treatment of HCC.

Findings of recent studies have demonstrated that many compounds from Traditional Chinese Medicine (TCM) are effective in the treatment of malignant tumors, including HCC (2-4). In a previous study, we found that Ganzaoning granule, a Traditional Chinese Medicine formula, is able to inhibit diethylnitrosamine-induced hepatocarcinogenesis in rat $(5,6)$. However, the active ingredients of Ganzaoning exerting an anti-HCC effect have not been clarified. Diosgenin, a steroidal saponin, is abundant in a variety of plants, such as yam (Dioscorea villosa) which is a main drug in Ganzaoning granule. Results of recent studies have shown that diosgenin exerts anticancer effects against a wide variety of tumor cells, including leukemic, gastric, colorectal, and breast cancer (7-11). However, the anticancer effect of diosgenin on HCC and the mechanisms has not been completely elucidated.

Therefore, we investigated the inhibitory effect of diosgenin on HCC, and the molecular mechanism of the antitumor effect in this study. Our results showed that diosgenin reduced the proliferation of Bel-7402, SMMC-7721 and HepG2 cells in a dose-dependent manner. In addition, diosgenin exerted an anti-proliferative effect in the three $\mathrm{HCC}$ cells by inducing G2/M cell cycle arrest and apoptosis. Furthermore, diosgenin upregulated p27 and p21 expression and activated the caspase cascade. Diosgenin-induced p27 and p21 upregulation was independent of $\mathrm{p} 53$. The results suggest that diosgenin 
potentially exerts chemopreventive effects on the relevant cell cycle regulation and death receptor apoptotic pathways.

\section{Materials and methods}

Cell culture and drug treatment. SMMC-7721, Bel-7402, HepG2 HCC cell lines were cultured in DMEM medium (HyClone, Logan, UT, USA) supplemented with $10 \%$ fetal bovine serum (FBS) (Biowest, Nuaille, France). The cells were cultured at $37^{\circ} \mathrm{C}$ with $5 \% \mathrm{CO}_{2}$. Diosgenin, with a purity of $>98 \%$ was purchased from Shanghai Winherb Medical Technology Co., Ltd. (Shanghai, China) and dissolved in ethanol.

MTT assay. The cells were seeded in 96-well plates and treated with diosgenin at concentrations of $0-40 \mu \mathrm{M}$ for the indicated time-points. After the exposure period, the media were removed. Cell viability was measured using the MTT method as previously described (12). The experiment was performed in triplicate. The inhibitory rate was calculated as a percentage using the formula: $\left(1-\mathrm{OD}_{\text {diosgenin }} / \mathrm{OD}_{\text {control }}\right) \times 100 \%$.

Cell morphology was observed under an inverted microscope and the images were obtained at amagnification of x 200 .

Cell cycle and apoptosis assay. Flow cytometric analysis was performed to determine the presence of cell cycle arrest and apoptotic cells. After treatment with diosgenin for $24 \mathrm{~h}$, the cells were collected by trypsinisation and washed twice with PBS, fixed in ice-cold $80 \%$ ethanol, and stored overnight at $4^{\circ} \mathrm{C}$. For analysis, the cells were washed with PBS twice, and suspended in $1 \mathrm{ml}$ of cold propidium iodide (PI) solution. The cells were then incubated on ice for $30 \mathrm{~min}$ in the dark and then analyzed using flow cytometry.

FITC-labeled Annexin V/PI staining was performed according to the manufacturer's instructions (Keygen, Nanjing, China). Briefly, $1 \times 10^{6}$ cells/well were suspended in buffer containing FITC-conjugated Annexin V/PI at appropriate concentrations. The samples were analyzed by flow cytometry and 20,000 events from each sample were obtained to ensure adequate data.

Quantitative RT-PCR. Total RNA was extracted from SMMC-7721 cells after diosgenin treatment with TRIzol reagent (Invitrogen, Carlsbad, CA, USA) according to the manufacturer's instructions. Total RNA $(5 \mu \mathrm{g})$ was reversetranscribed into cDNA using a first-strand cDNA synthesis kit (FSK-100) (Toyobo, Osaka, Japan). Amplification of the cDNA was achieved in triplicate using a commercially available SYBR-Green PCR Master mix (Toyobo). cDNA was amplified under the following conditions: $95^{\circ} \mathrm{C}$ for $5 \mathrm{~min}$ for denaturation and subjected to 40 cycles of $95^{\circ} \mathrm{C}$ for $10 \mathrm{sec}, 60^{\circ} \mathrm{C}$ for $20 \mathrm{sec}$, and $72^{\circ} \mathrm{C}$ for $25 \mathrm{sec}$. The relative expression level of mRNA in each sample was normalized to its $\beta$-actin content. The relative expression levels of mRNA were calculated as $2^{-\Delta \Delta C t}$.

Western blotting. SMMC-7721 cells were seeded in 6-well plates at a density of $1 \times 10^{6}$ cells/well with $2 \mathrm{ml}$ completed DMEM medium. Following diosgenin treatment for the indicated times, total protein was extracted as previously described $(12,13)$. The protein concentration was determined using the BCA method. Equal quantities of proteins were separated by sodium dodecyl sulfate polyacrylamide gel electrophoresis (SDS-PAGE) and transferred by electroblotting onto a nitrocellulose membrane. The membrane was blocked with 5\% BSA in TBST buffer $(20 \mathrm{mM}$ Tris- $\mathrm{HCl}, \mathrm{pH} 7.4$, $150 \mathrm{mM} \mathrm{NaCl}$ and $0.1 \%$ Tween-20) overnight at $4^{\circ} \mathrm{C}$. The membrane was incubated with specific primary antibodies for $2 \mathrm{~h}$ and a secondary antibody for $1 \mathrm{~h}$. The signal was visualized with an enhanced chemiluminescence kit (ECL) (Thermo Scientific, San Jose, CA, USA).

Statistical analysis. Data are presented as means \pm SD. Statistical significance was determined using SPSS 17.0 for Windows. The Student's t-test was used to compare means for two groups and one-way ANOVA was performed for multiple comparisons followed by the Newman-Keuls test for multiple comparisons. Differences were considered significant when $\mathrm{P}<0.05$.

\section{Results}

Diosgenin inhibits HCC cell proliferation. Diosgenin treatment for 24 and $48 \mathrm{~h}$ induced changes in SMMC-7721 cell morphology, including cell shrinkage, disappearance of tentacles and round-up shapes, indicating cell damage (Fig. 1A). The effect of diosgenin was concentration- and time-dependent. We examined the inhibitory rate of diosgenin in Bel-7721, SMMC-7721 and HepG2 HCC cells. The results showed that diosgenin treatment significantly inhibited Bel-7721, SMMC-7721 and HepG2 cell proliferation in a concentration-dependent manner (Fig. 1B).

Diosgenin induced G2/M cell cycle arrest and apoptosis of HCC cells. To investigate the mechanisms of diosgenin-induced growth repression, the flow cytometric analysis was performed. Diosgenin treatment caused a concentration-dependent increase of G2/M phase cell population in Bel-7721, SMMC7721 and HepG2 HCC cells, indicating diosgenin was able to arrest the cell cycle in G2/M phase (Fig. 2). The proportion of $\mathrm{G} 2 / \mathrm{M}$ phase cells increased with concentration of diosgenin.

We also determined whether diosgenin-induced HCC cell proliferation and inhibition involved apoptosis. Flow cytometry using Annexin V-PI staining was performed. After treatment with different concentrations of diosgenin for $24 \mathrm{~h}$, the proportions of apoptotic cells were markedly increased in Bel-7721, SMMC-7721 and HepG2 HCC cells (Fig. 3), suggesting that diosgenin was able to induce the HCC cell apoptosis. The effect of diosgenin on HCC cell apoptosis was concentration-dependent.

Effect of diosgenin on cell cycle-related proteins. To investigate the mechanisms of diosgenin-induced cell cycle arrest, we examined the expression of cell cycle-related proteins by quantitative RT-PCR and western blotting. Diosgenin $(40 \mu \mathrm{M})$ treatment for $24 \mathrm{~h}$ significantly upregulated the p21 and p27 mRNA levels in SMMC-7721 cells (Fig. 4A). Following treatment with diosgenin for $24 \mathrm{~h}$, Akt phosphorylation was significantly inhibited in SMMC-7721 cells in a concentration-dependent manner (Fig. 4B). p21 and p27 protein levels were significantly upregulated after diosgenin treatment in a 


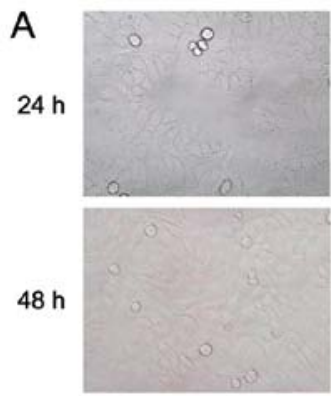

B

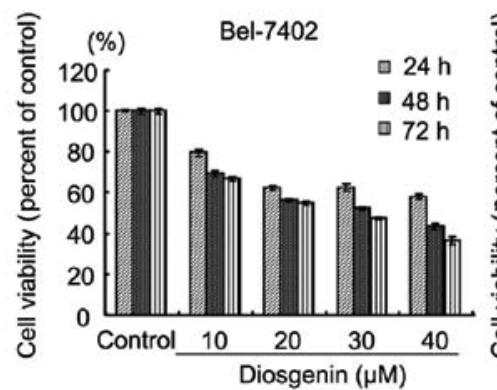

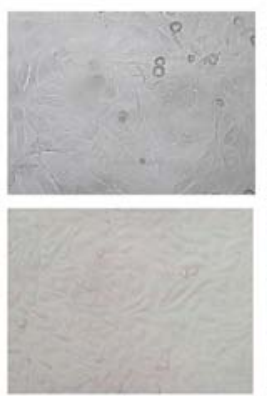

$10 \mu \mathrm{M}$

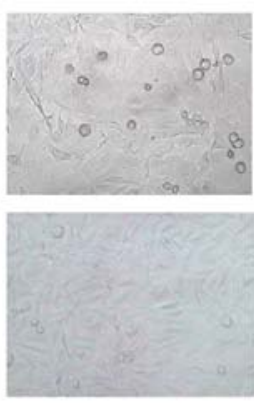

$20 \mu \mathrm{M}$

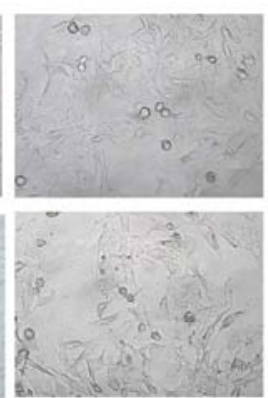

$30 \mu \mathrm{M}$

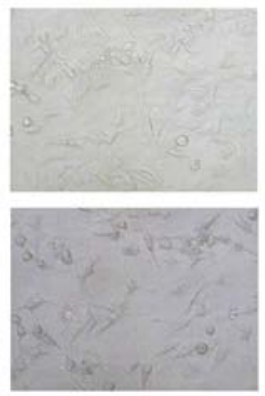

$40 \mu \mathrm{M}$
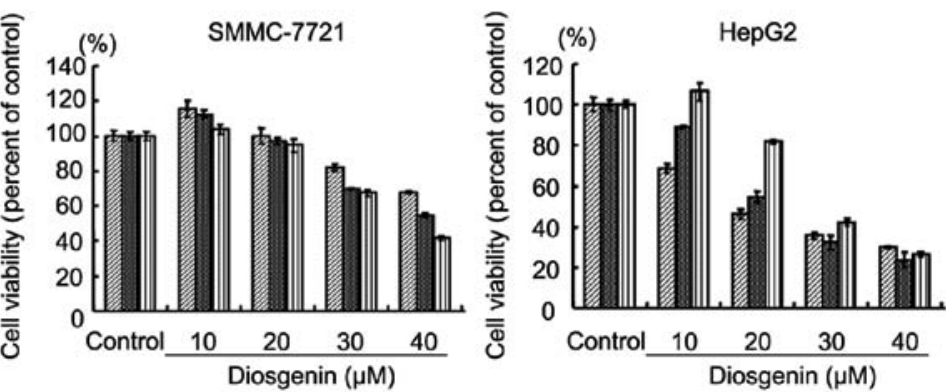

Figure 1. Diosgenin inhibited viability of SMMC-7721 cells. (A) SMMC-7721 cells were treated with the indicated concentrations of diosgenin for 24 or $48 \mathrm{~h}$ Cell morphology was observed under an inverted microscope and images were obtained (magnification, x200). (B) Bel-7402, SMMC-7721 and HepG2 cells were seeded in 96-well plates at a density of $1 \times 10^{4}$ cells/well with $100 \mu \mathrm{l}$ completed DMEM medium. After $24 \mathrm{~h}$, different concentrations of diosgenin were added into the wells and further cultured for 24,48 or $72 \mathrm{~h}$. MTT assay was then performed to determine cell proliferation. Data are presented as mean \pm SD $(\mathrm{n}=6)$. The experiments were repeated at least three times.
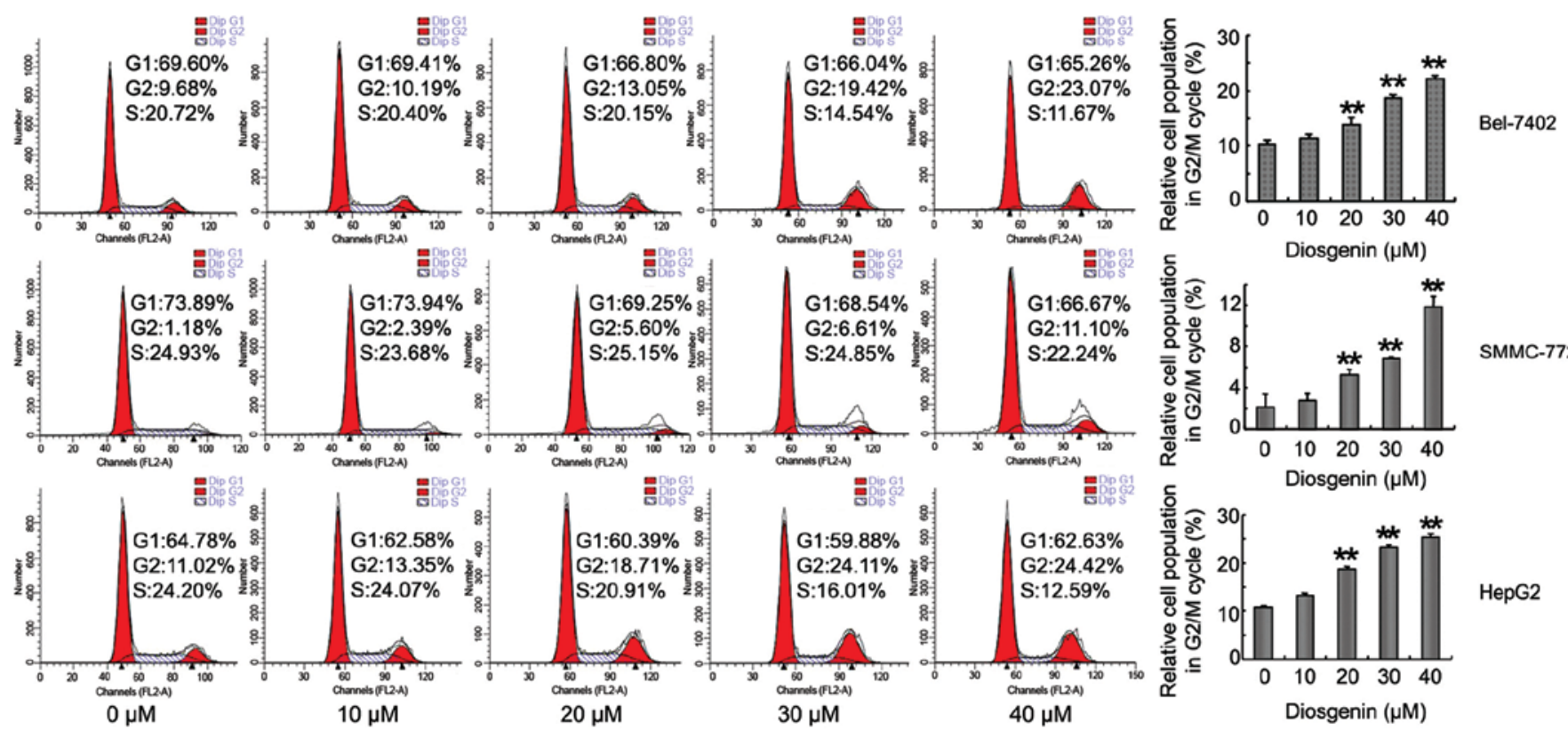

Figure 2. Diosgenin induced G2/M cell cycle arrest of HCC cells. Bel-7402, SMMC-7721 and HepG2 cells were seeded in 6-well plates at a density of $1 \times 10^{6}$ cells/well with $2 \mathrm{ml}$ completed DMEM medium. After $24 \mathrm{~h}$, diosgenin was added into the wells and incubated for another $24 \mathrm{~h}$. Then the cell cycle was determined by flow cytometry. Each bar shows the mean $\pm \mathrm{SD}(\mathrm{n}=3) .{ }^{*} \mathrm{P}<0.05,{ }^{* *} \mathrm{P}<0.01$, compared with control.

concentration-dependent manner. However, diosgenin treatment did not alter the expression of p53 in the mRNA and protein levels (Fig. 4A and B).

Effects of diosgenin on cell apoptosis-related proteins. To determine the signaling pathway responsible for diosgenin- induced apoptosis in HCC cells, the expression levels of apoptosis-related proteins were examined subsequently. We first examined whether diosgenin could alter the balance between pro-apoptotic protein Bax and anti-apoptotic protein Bcl-2 in SMMC-7721 cells. The results showed that diosgenin treatment did not alter Bax and Bcl-2 levels (Fig. 5). 

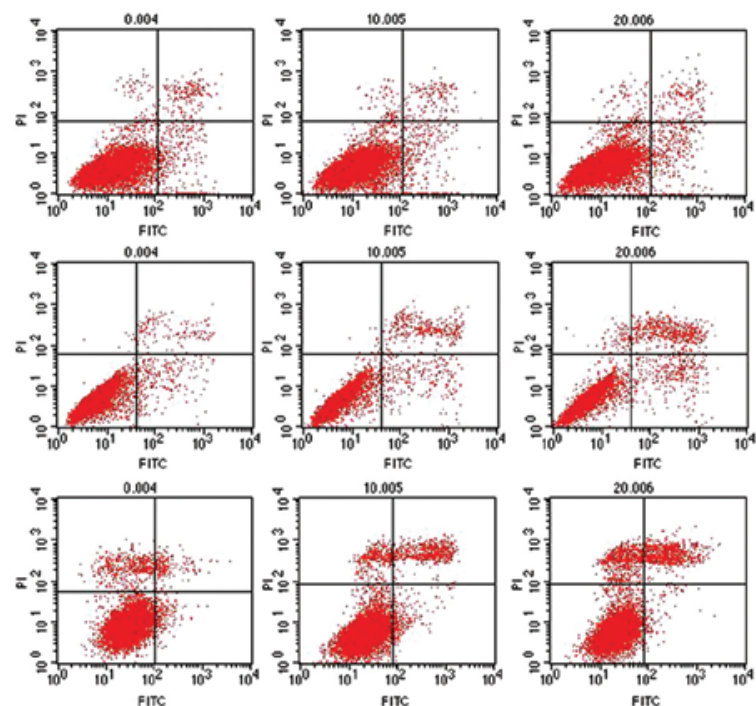

$0 \mu \mathrm{M}$

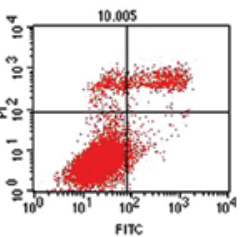

$10 \mu \mathrm{M}$

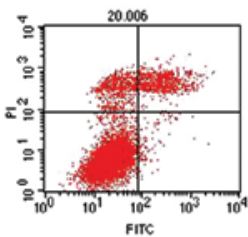

$20 \mu \mathrm{M}$
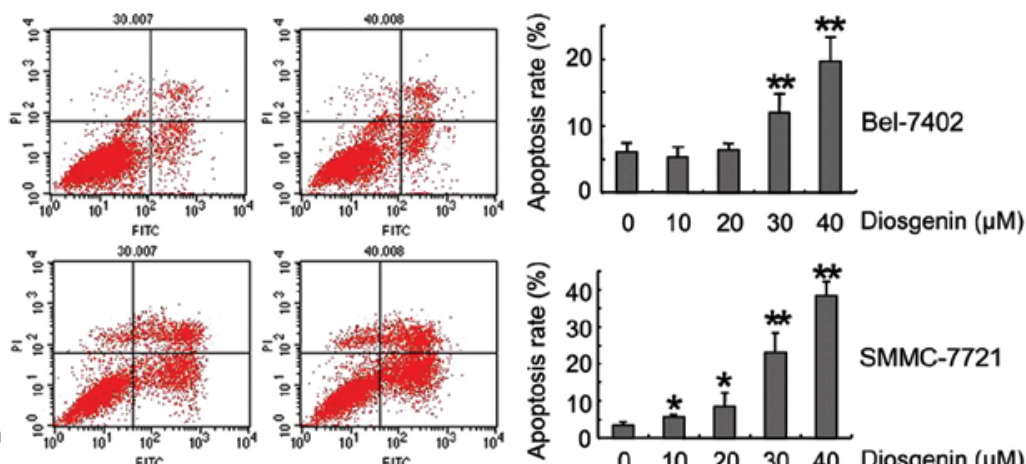

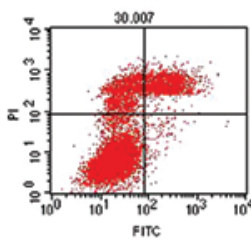

$30 \mu \mathrm{M}$

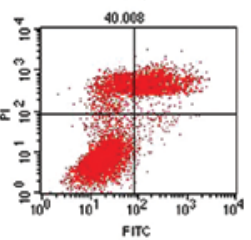

$40 \mu \mathrm{M}$

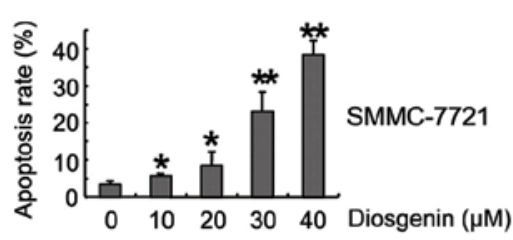

Figure 3. Diosgenin induced apoptosis of HCC cells. Bel-7402, SMMC-7721 and HepG2 cells were seeded in 6-well plates at a density of 1x10 ${ }^{6}$ cells/well with $2 \mathrm{ml}$ completed DMEM medium. After $24 \mathrm{~h}$, diosgenin was added into the wells and incubated for another $24 \mathrm{~h}$. The cells were stained with Annexin V/PI and analyzed by flow cytometry. Each bar shows the mean $\pm \mathrm{SD}(\mathrm{n}=3) .{ }^{*} \mathrm{P}<0.05,{ }^{* *} \mathrm{P}<0.01$, compared with control.

A
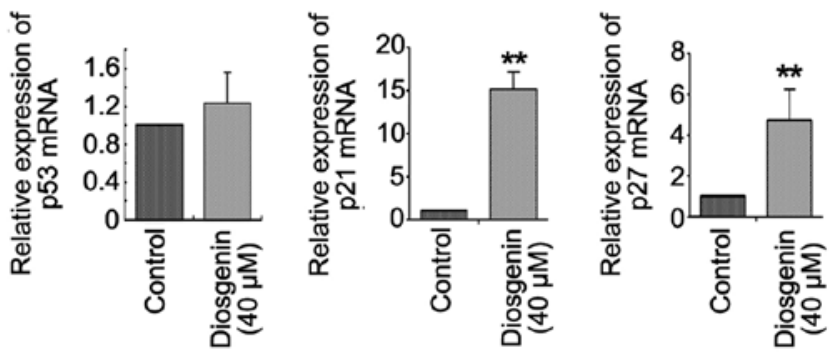

B

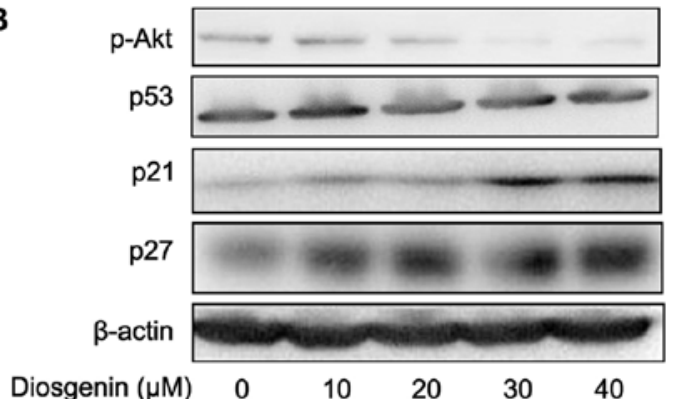

Figure 4. Effect of diosgenin on cell cycle-related proteins. (A) The mRNA levels of p53,p21 and p27 after diosgenin treatment. After diosgenin treatment for $24 \mathrm{~h}$, total RNA was isolated and quantitative RT-PCR was performed. The relative expression of p53,p21 and p27 was normalized with $\beta$-actin. Each bar shows the mean $\pm \mathrm{SD}(\mathrm{n}=3) .{ }^{*} \mathrm{P}<0.05,{ }^{* *} \mathrm{P}<0.01$, compared with the control. (B) Effect of diosgenin on cell cycle-related proteins. After diosgenin treatment for $24 \mathrm{~h}$, total protein was isolated and western blotting was performed.

The expression levels of caspase-3, -8 and -9 were also detected in diosgenin-treated SMMC-7721 cells. After various concentrations of diosgenin treatment for $24 \mathrm{~h}$, the expression of caspase-3, -8 and -9 was markedly reduced in a concentration-dependent manner (Fig. 5), whereas the cleaved caspase-3, -8 and -9 were obviously increased.

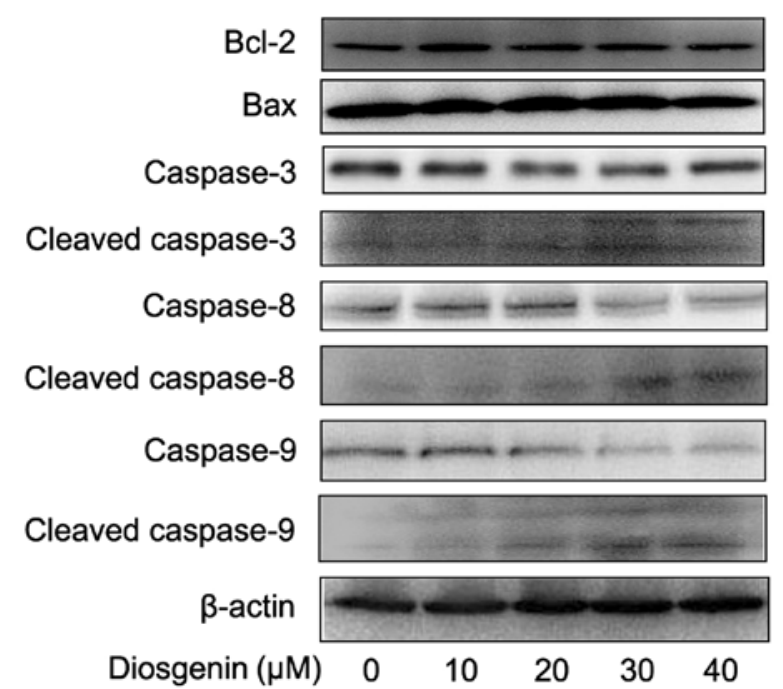

Figure 5. Effects of diosgenin on cell apoptotic-associated proteins. After diosgenin treatment for $24 \mathrm{~h}$, total protein was isolated and cell apoptoticassociated proteins were determined by western blotting.

\section{Discussion}

In the present study, we investigated the anti-HCC effect of diosgenin in three HCC cell lines. The results demonstrated that diosgenin exerted a strong growth inhibitory activity against Bel-7402,SMMC-7721 and HepG2 human liver cancer cells. Diosgenin induced G2/M cell cycle arrest and apoptosis in these cells. Further study showed that the upregulation of cell cycle-related proteins, p21 and p27, and activation of caspase cascade may be involved in diosgenin-induced cell cycle arrest and apoptosis.

Although the anticancer property of diosgenin has been widely reported in many cancer cells, the anti-HCC effect and the mechanisms involved in diosgenin have not been extensively investigated. In the present study, the results showed that 
diosgenin inhibited the proliferation of Bel-7402, SMMC-7721 and HepG2 HCC cells. We also studied the mechanisms of diosgenin at cellular and molecular levels. It is well recognized that dysregulation of the cell cycle is a hallmark of tumor cells. Numerous anticancer drugs play a therapeutic role by inducing cell cycle arrest. In the present study, we showed that treatment with diosgenin induced G2/M cell cycle arrest in Bel-7402, SMMC-7721 and HepG2 cells in a concentration-dependent manner. Although previous studies showed that diosgenin treatment caused cell cycle arrest in G1 phase in osteosarcoma cells and C3A hepatoma cells $(14,15)$, diosgenin also induced G2/M cell cycle arrest in erythroleukemia HEL cells and human leukemia K562 cells $(9,16)$. Those results suggest that the action of diosgenin on cell cycle and its mechanism may be determined by the cell type.

The potent cyclin-dependent kinase inhibitors (CKI) (17), p21 and p27, negatively regulate multiple phases of the cell cycle progression (18). After binding to the Cyclin-Cdk complexes, p21 and p27 inhibit their kinase activities and prevent cell cycle progression (19). Since the upregulation of p21 and p27 suppresses the proliferation of many cancer cells by inducing cell cycle arrests, they are recognized as important tumor suppressors $(20,21)$. Diosgenin treatment induced a significant increase of p21 and p27 in SMMC-7721 cells, suggesting that the regulation of p21 and p27 may be involved in diosgenininduced cell cycle arrest. However, p53 expression, which is conventionally considered as a regulator of $\mathrm{p} 21$, was not altered by diosgenin, suggesting the diosgenin-induced upregulation of p21 and p27 is not p53-dependent. Phosphatidylinositol 3 kinase (PI3K)/Akt pathway is a vital regulator of cell survival, proliferation and migration (22). Deregulation of the PI3K/Akt signaling pathway is important in cancer development and has been suggested as a therapeutic target for cancer (22-24). The inhibition of PI3K/Akt pathway by its specific inhibitor LY294002 is able to upregulate the expression of p21 and p27 (25) and lead to cell cycle arrest (26). Diosgenin is known to suppress Akt activation in various cell types (27-29). Our data also showed that diosgenin treatment inhibited Akt phosphorylation. These results suggest that the inactivation of the PI3K/Akt pathway accompanied by an increased expression of p21 and p27 is involved in diosgenin-induced cell cycle arrest in HCC cells.

Cell growth is also regulated by apoptosis. Diosgenininduced $\mathrm{G} 2 / \mathrm{M}$ cell cycle arrest provides an opportunity for HCC cells to undergo apoptotic progression. In this study, flow cytometry showed that treatment with diosgenin caused concentration-dependent cell apoptosis. Since activation of the caspase cascade and its downstream molecules turns on cell apoptotic death progression, we first assessed the effect of diosgenin on the caspase cascade, which mediates the death receptor pathway. Western blotting showed that diosgenin decreased the total caspase-3, -8 and -9 levels, but increased the cleaved caspase- $3,-8$ and -9 levels in a concentration-dependent manner. The $\mathrm{Bcl}-2$ family proteins are crucial for mitochondrial pathway-induced apoptosis (30). Diosgenin treatment for $24 \mathrm{~h}$ did not alter the expression of pro-apoptotic protein Bax and anti-apoptotic protein Bcl-2. These results suggest that diosgenin-induced apoptosis of HCC cells may be mediated by the death receptor pathway, but not the mitochondrial pathway. Although Kim et al (31) reported that diosgenin induced apoptosis in HepG2 cells through the generation of reactive oxygen species and mitochondrial pathway, our results may indicate a diverse mechanism of diosgenin.

In conclusion, our study demonstrated that diosgenin inhibited HCC cell proliferation by inducing G2/M cell cycle arrest and apoptosis. The inactivation of Akt, upregulation of p21 and p27 expression and activation of the caspase cascades were involved in the anti-HCC effect of diosgenin. Therefore, our study may provide evidence for the anti-HCC effect of diosgenin and elucidate the underlying mechanisms of diosgenin.

\section{Acknowledgements}

This project was supported by grants from the National Natural Science Foundation of China (no. 81202973) and the E-Institutes of Shanghai Municipal Education Commission (no. E-03008).

\section{References}

1. Jemal A, Bray F, Center MM, Ferlay J, Ward E and Forman D: Global cancer statistics. CA Cancer J Clin 61: 69-90, 2011.

2. Paul A, Das S, Das J, et al: Diarylheptanoid-myricanone isolated from ethanolic extract of Myrica cerifera shows anticancer effects on HeLa and PC3 cell lines: signalling pathway and drug-DNA interaction. J Integr Med 11: 405-415, 2013.

3. Zhai XF, Chen Z, Li B, et al: Traditional herbal medicine in preventing recurrence after resection of small hepatocellular carcinoma: a multicenter randomized controlled trial. J Integr Med 11: 90-100, 2013.

4. Zhao L, Zhao AG, Zhao G, et al: Survival benefit of traditional Chinese herbal medicine (a herbal formula for invigorating spleen) in gastric cancer patients with peritoneal metastasis. Evid Based Complement Alternat Med 2014: 625493, 2014

5. Qian Y, Jin Y, Li Y and Ling C: Inhibitive effect of 981208 agent on cell proliferating of hepatocarcinogenesis induced by diethyl nitros-amine in rats. Acad J Sec Mil Med Univ 22: 558-560, 2001.

6. Qian Y, Jin Y, Li Y, Li B and Ling C: Experimental study of mechanism of Ganfujian granule inhibiting hepatocarcinogenesis induced with Diethylnitrosamine in rats. J Zhejiang Chin Med Univ 27: 56-58, 2003.

7. Mao ZJ, Tang QJ, Zhang CA, et al: Anti-proliferation and antiinvasion effects of diosgenin on gastric cancer BGC-823 cells with HIF-1 $\alpha$ shRNAs. Int J Mol Sci 13: 6521-6533, 2012.

8. He Z, Tian Y, Zhang X, et al: Anti-tumour and immunomodulating activities of diosgenin, a naturally occurring steroidal saponin. Nat Prod Res 26: 2243-2246, 2012.

9. Liu MJ, Wang Z, Ju Y, Wong RN and Wu QY: Diosgenin induces cell cycle arrest and apoptosis in human leukemia K562 cells with the disruption of $\mathrm{Ca}^{2+}$ homeostasis. Cancer Chemother Pharmacol 55: 79-90, 2005.

10. Lepage C, Leger DY, Bertrand J, Martin F, Beneytout JL and Liagre B: Diosgenin induces death receptor-5 through activation of p38 pathway and promotes TRAIL-induced apoptosis in colon cancer cells. Cancer Lett 301: 193-202, 2011.

11. He Z, Chen H, Li G, et al: Diosgenin inhibits the migration of human breast cancer MDA-MB-231 cells by suppressing Vav2 activity. Phytomedicine 21: 871-876, 2014.

12. Du J, Cheng B, Zhu X and Ling C: Ginsenoside Rg1, a novel glucocorticoid receptor agonist of plant origin, maintains glucocorticoid efficacy with reduced side effects. J Immunol 187: 942-950, 2011.

13. Binbin C, Yinglu F, Juan D and Changquan L: Upregulation effect of ginsenosides on glucocorticoid receptor in rat liver. Horm Metab Res 41: 531-536, 2009.

14. Li F, Fernandez PP, Rajendran P, Hui KM and Sethi G: Diosgenin, a steroidal saponin, inhibits STAT3 signaling pathway leading to suppression of proliferation and chemosensitization of human hepatocellular carcinoma cells. Cancer Lett 292: 197-207, 2010.

15. Moalic S, Liagre B, Corbiere C, et al: A plant steroid, diosgenin, induces apoptosis, cell cycle arrest and COX activity in osteosarcoma cells. FEBS Lett 506: 225-230, 2001. 
16. Leger DY, Liagre B, Corbiere C, Cook-Moreau J and Beneytout JL: Diosgenin induces cell cycle arrest and apoptosis in HEL cells with increase in intracellular calcium level, activation of cPLA2 and COX-2 overexpression. Int J Oncol 25: $555-562,2004$.

17. Satyanarayana A, Hilton MB and Kaldis P: p21 inhibits Cdk1 in the absence of Cdk2 to maintain the G1/S phase DNA damage checkpoint. Mol Biol Cell 19: 65-77, 2008.

18. Chan TA, Hwang PM, Hermeking H, Kinzler KW and Vogelstein B: Cooperative effects of genes controlling the G(2)/M checkpoint. Genes Dev 14: 1584-1588, 2000.

19. Lee E, Kwak GH, Kamble K and Kim HY: Methionine sulfoxide reductase B3 deficiency inhibits cell growth through the activation of p53-p21 and p27 pathways. Arch Biochem Biophys 547: $1-5,2014$.

20. Masgras I, Carrera S, de Verdier PJ, et al: Reactive oxygen species and mitochondrial sensitivity to oxidative stress determine induction of cancer cell death by $\mathrm{p} 21$. J Biol Chem 287: 9845-9854, 2012.

21. Yadav V, Sultana S, Yadav J and Saini N: Gatifloxacin induces $\mathrm{S}$ and G2-phase cell cycle arrest in pancreatic cancer cells via p21/p27/p53. PLoS One 7: e47796, 2012.

22. Pal I and Mandal M: PI3K and Akt as molecular targets for cancer therapy: current clinical outcomes. Acta Pharmacol Sin 33: 1441-1458, 2012.

23. Liang $\mathbf{J}$ and Slingerland JM: Multiple roles of the PI3K/PKB (Akt) pathway in cell cycle progression, Cell Cycle 2: 339-345, 2003 .
24. Osaki M, Oshimura M and Ito H: PI3K-Akt pathway: its functions and alterations in human cancer. Apoptosis 9: 667-676, 2004

25. Izutani Y, Yogosawa S, Sowa Y and Sakai T: Brassinin induces G1 phase arrest through increase of p21 and p27 by inhibition of the phosphatidylinositol 3-kinase signaling pathway in human colon cancer cells. Int J Oncol 40: 816-824, 2012.

26. Georgakis GV, Li Y, Rassidakis GZ, Medeiros LJ, Mills GB and Younes A: Inhibition of the phosphatidylinositol-3 kinase/ Akt promotes G1 cell cycle arrest and apoptosis in Hodgkin lymphoma. Br J Haematol 132: 503-511, 2006.

27. Leger DY, Liagre B and Beneytout JL: Role of MAPKs and $\mathrm{NF}-\kappa \mathrm{B}$ in diosgenin-induced megakaryocytic differentiation and subsequent apoptosis in HEL cells. Int $\mathbf{J}$ Oncol 28: 201-207, 2006

28. Shishodia S and Aggarwal BB: Diosgenin inhibits osteoclastogenesis, invasion, and proliferation through the downregulation of Akt, I kappa B kinase activation and NF-kappa B-regulated gene expression. Oncogene 25: 1463-1473, 2006.

29. Srinivasan S, Koduru S, Kumar R, Venguswamy G, Kyprianou N and Damodaran C: Diosgenin targets Akt-mediated prosurvival signaling in human breast cancer cells. Int J Cancer 125: 961-967, 2009.

30. Zinkel S, Gross A and Yang E: BCL2 family in DNA damage and cell cycle control. Cell Death Differ 13: 1351-1359, 2006.

31. Kim DS, Jeon BK, Lee YE, Woo WH and Mun YJ: Diosgenin induces apoptosis in HepG2 cells through generation of reactive oxygen species and mitochondrial pathway. Evid Based Complement Alternat Med 2012: 981675, 2012. 